\title{
Muses and Longevity
}

\section{Anisimov VN ${ }^{1 *}$ and Zharinov $\mathbf{G M}^{2}$}

${ }^{1}$ N.N. Petrov Research Institute of Oncology, St.Petersburg, Russia

${ }^{2}$ Russian Scientific Center of Radiology and Surgery Technologies, St.Petersburg, Russia

There are common opinion that at least $65-70 \%$ of rate of aging and longevity of humans determined by social and economic conditions and life style $[1,2]$ whereas genetic factors have an important but significantly smaller impact on aging [3]. Some professions (lorry drivers, miners, seamen, Cherbobyl's liquidators, etc.) have a features of accelerated aging and increased risk of premature death [2]. At the same time, persons which received signs of their success or excellence from a state or from professional societies (Nobel prize winners, Oscar or popular competitions winners, members of national academies, etc) live longer than ordinary citizens [4-6]. Intriguing finding is a persistence of cognitive capacities in musicians performed classic music [7], whereas jazzmen live shorter [8].

The data on mean age of death of 49064 representatives of various creative professions: visual artists (painters, sculptors, architects, $\mathrm{n}=8458$ ), musicians (composers, conductors, singers, pianists, violinists, etc., $n=7883)$, writers and poets $(n=11488)$, scholars $(n=21235)$ have been analyzed [9]. The mean age of death among writers and poets was significantly less than that in visual artists, musicians and scholars whereas scholars lives longer than representatives of other categories. Women lived longer than men in any studied categories. The first five places of long-livers among men belong to Nobel prize winners (78.8 yrs.), academicians (72.7 yrs.) and corresponding members of the Russian Academy of Sciences (71.7 yrs.), conductors (71.1 yrs.) and scholars (71.0 yrs.). Rock-musicians, author's song singer and poets lived less other categories (43.6; 53.6 and 61.6 yrs. respectively). Among women leading long-livers were conductors (83.2 yrs.), harpplayers ( $80.9 \mathrm{yrs}$.), academicians of the RAS ( $80.3 \mathrm{yrs}$ ), clavesin-players (79.1 yrs.) and violinists (78.2 yrs.). Among women, less than other lived rock-musicians (37,6 yrs.), author's songs singers (51.4), horns and woodwinds instruments players (59.0 yrs.). Relative number of nonagenarians $(90+)$ was much higher among women as compared to men. The values were as $43.8 \%$ of harp-players, $33.3 \%$ of conductors, $29.27 \%$ of architects, $20 \%$ of violinists and viola-players and $19.0 \%$ sculptors for women, and $16.7 \%$ of Nobel prize winners, $12.1 \%$ of conductors, $7.5 \%$ of academicians, $7.4 \%$ of violinists and $7.0 \%$ of scholars survived $90+$ years among men. Centenarians were $8.33 \%$ of academicians and architects, $6.3 \%$ of harp-players and $4.2 \%$ of writerspoets among women, and only $0.7 \%$ of pianists, $0.5 \%$ of scholars and $0.4 \%$ of violinists were centenarians among men. Our data are in agreement with the opinion that high intellect and education directly correlate with longer life span and longevity [10,11]. It is possible to suggest that persons who prefer to listen to classic music have more chance to live longer. The reasons of the differences in the life span of persons involved in various creative professions needs to be studied (Figure 1).

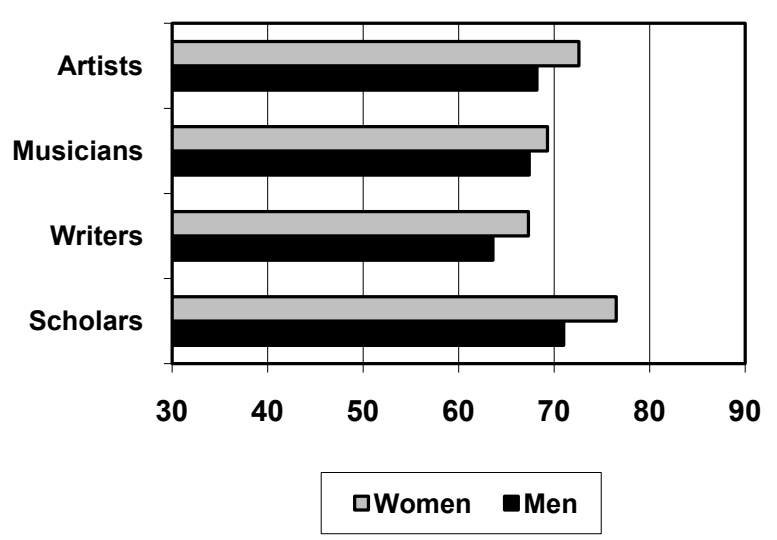

Figure 1: Mean age (years) at death of representatives of various creative professions.

\section{References}

1. Schulz-Aellen MF (1997) Aging and Human Longevity. Boston: Birkhauser.

2. Anisimov VN (2008) Molecular and Physiological Mechanisms of Aging (2ndedn). St.Petersburg: Nauka.

3. Finch CE (1990) Longevity, Senescence, and the Genome. Chicago: Univ Chicago Press.

4. Anisimov VN, Mikhal'ski Al (2004) [Are Nobel prize winners gettting older? Mathematical analysis of age and life span of the Nobel prize winners, 1901 2003]. Adv Gerontol 15: 14-22.

5. Andreev EM, Jdanov D, Shkolnikov VM, Leon DA (2011) Long-term trends in the longevity of scientific elites: evidence from the British and the Russian academies of science. Popul Stud (Camb) 65: 319-334.

6. Redelmeier DA, Singh SM (2001) Survival in Academy Award-winning actors and actresses. Ann Intern Med 134: 955-962.

7. Hanna-Pladdy B, MacKay A (2011) The relation between instrumental musica activity and cognitive aging. Neuropsychology 25: 378-386.

8. Spencer FJ (1991) Premature death in jazz musicians: fact or fiction? Am J Public Health 81: 804-805.

9. Anisimov VN, Zharinov GM (2013) Life span and longevity in representatives of creative professions. Adv Gerontol 26: 405-416.

10. Cassandro VJ (1998) Explaining premature mortality across fields of creative endeavor. J Pers 66: 805-833.

11. Steen G, Berg S, Steen B (1998) Cognitive function in 70-year-old men and women. A 16-year cohort difference population study. Aging (Milano) 10: 120126.

*Corresponding author: Anisimov VN, N.N. Petrov Research Institute of Oncology, St.Petersburg, Russia, Tel: 812- 596-6539; E-mail: aging@mail.ru

Received October 31, 2013; Accepted November 01, 2013; Published November 04,2013

Citation: Anisimov VN, Zharinov GM (2013) Muses and Longevity. J Gerontol Geriat Res 2: e123. doi:10.4172/2167-7182.1000e123

Copyright: (c) 2013 Anisimov VN, et al. This is an open-access article distributed under the terms of the Creative Commons Attribution License, which permits unrestricted use, distribution, and reproduction in any medium, provided the original author and source are credited. 